TREATMENT OF IRRADIATION EFFECTS IN STRUCTURAL DESIGN CRITERIA FOR FUSION REACTORS*

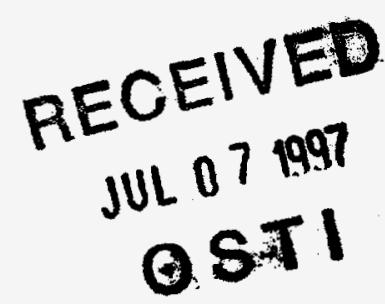

\author{
Saurin Majumdar \\ Fusion Power Program \\ Argonne National Laboratory \\ Argonne, IL 60439 USA \\ and \\ Peter Smith \\ ITER Joint Central Team \\ San Diego Joint Work Site \\ 11025 N. Torrey Pines Rd. \\ San Diego, CA 92037 USA
}

March, 1997

$$
\begin{aligned}
& \text { ANL/ET/CP-93432 } \\
& \text { CONF-970404- }-12
\end{aligned}
$$




\section{DISCLAIMER}

This report was prepared as an account of work sponsored by an agency of the United States Government. Neither the United States Government nor any agency thereof, nor any of their employees, make any warranty, express or implied, or assumes any legal liability or responsibility for the accuracy, completeness, or usefulness of any information, apparatus, product, or process disclosed, or represents that its use would not infringe privately owned rights. Reference herein to any specific commercial product, process, or service by trade name, trademark, manufacturer, or otherwise does not necessarily constitute or imply its endorsement, recommendation, or favoring by the United States Government or any agency thereof. The views and opinions of authors expressed herein do not necessarily state or reflect those of the United States Government or any agency thereof. 


\section{DISCLAMIER}

Portions of this document may be illegible in electronic image products. Images are produced from the best available original document. 


\title{
TREATMENT OF IRRADIATION EFFECTS IN STRUCTURAL DESIGN CRITERIA FOR FUSION REACTORS*
}

\author{
Saurin Majumdar \\ Fusion Power Program \\ Argonne National Laboratory \\ Argonne, IL 60439 USA \\ and \\ Peter Smith \\ ITER Joint Central Team \\ San Diego Joint Work Site \\ 11025 N. Torrey Pines Rd. \\ San Diego, CA 92037 USA
}

\subsection{Introduction}

The irradiation environment experienced by the in-vessel components of fusion reactors such as the International Thermonuclear Experimental Reactor (ITER) presents structural design challenges not envisioned in the development of existing structural design criteria such as the ASME Code [1] or RCC-MR [2]. From the standpoint of structural design criteria, the most significant issues stem from the irradiation-induced changes in material properties, specifically the reduction of ductility, strain hardening capability, and fracture toughness with neutron irradiation. These effects call into question the basis of the design rules in existing structural design criteria which assume that only code-approved materials with high toughness, ductility and strain hardening capability will be used. The present paper reviews the basis of new rules that address these issues in Draft 5 of the interim ITER structural design criteria (ISDC) which was released recently for trial use by the ITER designers.

\footnotetext{
* Work supported by Office of Fusion Energy, U.S. Department of Energy, under Contract No W-31-109Eng-38.
} 


\subsection{Irradiation effects on material properties}

Since most near-term fusion reactors such as ITER will use austenitic stainless steel as structural material, the present paper will focus on this material. Austenitic stainless steels are known to be embrittled by fission neutron environment. Such effects may be further exacerbated by significant generation of transmutation products like He under fusion neutron environment. Typical stress-strain curves for fission reactor irradiated type 316 stainless steel at room temperature are shown in Fig. 1 [3]. Three things are to be noted:

(1) The material hardens significantly with fluence; the yield strength $\left(S_{y}\right)$ increases by a factor of 3-4 compared to the unirradiated value.

(2) The strain hardening capability decreases with fluence; the material behaves essentially as an elastic-perfectly-plastic material beyond a fluence of $5 \mathrm{dpa}$.

(3) Both the total and uniform elongation $\left(\varepsilon_{u}\right)$ decrease with fluence; in particular, the uniform elongation reaches a very low value at $10 \mathrm{dpa}$.

In addition to tensile properties, fracture toughness and fatigue crack growth resistance properties of some (not all) stainless steels may also decrease significantly by neutron fluence [4-5]. Stainless steels also exhibit irradiation-induced creep and swelling, although for first walls operating at low temperatures $\left(\leq 350^{\circ} \mathrm{C}\right)$, swelling should not be a problem.

\subsection{Elastic follow up factor (r-factor)}

The design rules in existing design criteria such as the ASME Code and RCC-MR are based on limit analysis of plasticity which assumes that materials have unlimited ductility. The new elastic-analysis design rules that are proposed in the ISDC consider materials with reduced ductility and are based on the concept of elastic follow up factor [6-7]. Consider a generic point in a structure where the elastically calculated stress and strain are denoted by $\sigma_{\mathrm{el}}$ and $\varepsilon_{\mathrm{el}}$, respectively and the actual stress and strain are denoted by $\sigma_{\mathrm{N}}$ and $\varepsilon_{\mathrm{N}}$, respectively (Fig. 2). Define the abscissa of the point of intersection of the strain axis with the extended line joining the elastic point to the actual stress-strain point $\left(\varepsilon_{N}, \sigma_{N}\right)$ (Fig. 2) as $r \varepsilon_{\text {el }}$ where $r$ is the elastic follow up factor. Then $r$ can be shown to be given by the following: 


$$
r=\frac{E \varepsilon_{N}-\sigma_{N}}{\sigma_{e l}-\sigma_{N}}
$$

where $\mathrm{E}$ is the Young's modulus. Equation 1 can be rewritten in terms of the actual plastic strain $\varepsilon_{\mathrm{pl}}$ as follows:

$$
\sigma_{\mathrm{e} 1}=\sigma_{\mathrm{N}}+\frac{\mathrm{E} \varepsilon_{\mathrm{pl}}}{\mathrm{r}}
$$

For purely secondary stresses, $\mathrm{r}=1$ and for purely primary stresses, $\mathrm{r}=\infty$. In general, $\mathrm{r}$ depends on the geometry, load level, and the stress-strain curve of the material. For a large variety of structures, the value of $r$ can be bounded, which effectively allows the actual stress and strain in the structure to be estimated conservatively.

\subsection{Analytical solutions for $r$ factor}

Closed form analytical solution for the r-factor has been obtained for displacementcontrolled three-point bend loading of a beam with bilinear stress-strain curve. The results plotted in fig. 3 clearly show that $r$ remains bounded as long as the material is strain hardening, but is unbounded when it is elastic-perfectly-plastic $\left(E_{T}=0\right)$. An analytical expression for $\mathbf{r}$-factor can be established approximately by using Neuber's rule for the tensile loading of a notched bar with a stress concentration factor $\mathrm{K}_{\mathrm{T}}$ :

$$
\mathrm{r}=\left(\mathrm{K}_{\mathrm{T}}\right)^{\frac{1-\mathrm{n}}{1+\mathrm{n}}}
$$

where $\mathrm{n}$ is the strain hardening exponent. Because of the constraining effects of the notch, $r$ remains bounded for the perfectly plastic case $(n=0)$.

Equation (1) has been applied to a large number of components by Roche [6], Iida et al. [7], and Takakura et al.[8] for creep-fatigue analysis. The analyses confirmed that, as long as the stresses were within the design allowable limits, the value of $r$ was always significantly less than 3 . However, the $r$-factor approach has not generally been applied to higher load levels. 


\subsection{Experimental determination of $r$ factor}

A number of three-point bend tests (1.5 in. span, 0.04 in. thick and $0.5 \mathrm{in}$. wide) and notched (stress concentration factor $\mathrm{K}_{\mathrm{T}}=4$ ) tensile tests on irradiated type 304 stainless steel were conducted by Garkisch, Fish, and Haglund [9] and Fish [10], respectively. Using their test data and tensile properties of the irradiated material, the values of $r$ at rupture can be calculated and plotted against the uniform elongation (representing the strain hardening of the material), as shown in Fig. 4. Except for a few points, the analytically calculated $r$ values for the same tests compare reasonably well with the experimentally determined r values (Figs. 4-5). Note that the trend curve in Fig. 4 for the three-point bend tests confirms the analytical prediction that although the $r$ value can be very large for low uniform elongation (i.e., low strain hardening), it decreases with increasing uniform elongation.

In the ISDC, the value of the $\mathrm{r}$ factor away from notch roots is set conservatively equal to $\infty$ whenever the uniform elongation drops below $2 \%$. For materials with uniform elongation $>2 \%$, the value of $r$ factor is set equal to the greater of 4 and $\mathrm{K}_{\mathrm{T}}$.

\subsection{Irradiation effects on structural damage}

The basic structural damages (excluding buckling) have been broadly categorized in the ISDC as belonging to either M-type (monotonic) damage or C-type (cyclic) damage, depending on whether they can potentially cause structural failure during the first application of the loading or by repeated application of the loading, respectively. Although both types of damages are considered in all structural design criteria, this classification is explicitly used to organize the design rules in the RCC-MR and has also been followed in the ISDC.

\subsection{Necking and plastic collapse}

To prevent damage by necking and plastic collapse, both the RCC-MR [2] and the ASME Code [1] require that the primary membrane $\left(\mathrm{P}_{\mathrm{m}}\right.$ and $\left.\mathrm{P}_{\mathrm{L}}\right)$ and bending $\left(\mathrm{P}_{\mathrm{b}}\right)$ stress intensities satisfy the following two limits :

$$
\begin{aligned}
& \mathrm{P}_{\mathrm{m}}<\mathrm{S}_{\mathrm{m}} \\
& \mathrm{P}_{\mathrm{L}}+\mathrm{P}_{\mathrm{b}}<K \mathrm{~S}_{\mathrm{m}}
\end{aligned}
$$


where $S_{m}$ is the allowable primary membrane stress intensity (depends on the yield and ultimate tensile strengths) and $\mathrm{K}$ is the bending shape factor ( $=1.5$ for solid rectangular section). Because of possible loss of irradiation hardening due to cyclic straining or thermal annealing, no advantage is taken in ISDC of an increased $\mathrm{S}_{\mathrm{m}}$ due to irradiation hardening. Further, to account for possible loss of ductility, the approach taken in the ISDC is to adopt an equation similar to Eq. (4b), but replacing $K$ by a $K_{\text {eff }}$ such that comparable safety factors are maintained. A simple model of a rectangular section beam of a material with bilinear stress-strain curve was used to derive an expression for $\mathrm{K}_{\mathrm{eff}}$, which reduces to $\mathrm{K}(=1.5)$ for infinite ductility and to 1 for zero ductility. However, for type 316 LN-IG austenitic stainless steel, the corrections for $\mathrm{K}_{\text {eff }}$ are rather small. For example, even though its uniform elongation drops rapidly from $10 \%$ to $0.3 \%$ beyond a threshold of $7 \mathrm{dpa}$ [3], the value of $\mathrm{K}_{\mathrm{eff}}$ for a solid rectangular section is reduced from 1.5 to only 1.38 .

\subsection{Plastic flow localization}

Plastic flow localization is a form of non-linear instability like necking which occurs in materials whose strain hardening capability has been reduced significantly by neutron irradiation. Generally, the effects of small surface imperfections are entirely local and do not affect the overall behavior of the structure because strain hardening homogenizes the plastic strain. On the other hand, the presence of small surface notches in a material with low strain hardening capability can lead to failure of the structure by plastic flow localization. Stated alternatively, the $r$ value for a structure made of such a material can be much higher than one made with a material with higher strain hardening capability. An example of flow localization obtained by the finite element analysis of a tensile specimen (with a small surface flaw) subjected to end displacement is shown in Fig. 6. Fig. 7 shows that the calculated (material modeled as bilinear with yield strength $S_{\mathrm{y}}$ and tangent modulus $\mathrm{E}_{\mathrm{T}}$ ) peak plastic strain on the surface opposite from that containing the notch increases rapidly with decreasing $\mathrm{E}_{\mathrm{T}}$ at $\mathrm{E}_{\mathrm{T}} / \mathrm{S}_{\mathrm{y}}=2$, which corresponds approximately to a uniform elongation of $2 \%$. Thus, very little strain hardening is needed to keep the plastic flow localization effects of the notch from spreading through the thickness. If the perturbation were caused in such a material by a long wavelength thickness variation rather than an abrupt notch, necking (which is also a form of flow localization) would be predicted. To prevent either form of damage from occurring in an irradiated material due to combined primary and secondary membrane stresses $\left(\overline{\mathrm{P}_{\mathrm{L}}\left(\text { or } \mathrm{P}_{\mathrm{m}}\right)+\mathrm{Q}_{\mathrm{L}}}\right)$, the following new rule $\left(\mathrm{S}_{\mathrm{e}}\right.$ rule without the safety factors), based on Eq. (2) and using the elastic follow up factor (rfactor), has been introduced in the ISDC. 


$$
S_{e}=S_{u}+\frac{E}{r_{1}}\left(\varepsilon_{u}-0.02\right)
$$

where $S_{u}$ is the ultimate tensile strength and

$$
\mathrm{r}_{1}=\left\{\begin{array}{l}
4 \text { if } \varepsilon_{\mathrm{u}} \geq 2 \% \\
\infty \text { if } \varepsilon_{\mathrm{u}}<2 \%
\end{array}\right.
$$

For unirradiated annealed austenitic stainless steels $\left(\varepsilon_{\mathrm{u}} \sim 20 \%\right)$, the numerical values of $\mathrm{S}_{\mathrm{e}}$ are orders of magnitude higher than the maximum stresses expected in ITER and Eq. (5a) is never controlling. It may become controlling only when the material is sufficiently embrittled by irradiation so that the uniform elongation is reduced significantly.

\subsection{Local fracture due to exhaustion of ductility}

Local fracture due to exhaustion of ductility can occur in irradiated materials in two ways. First, it can occur at zones of stress concentration where, due to local plastic flow and high triaxiality of the stress field, the available ductility may become depleted. Second, it can occur in areas of high elastic follow up. To prevent both types of damage from occurring, the following new rule ( $S_{d}$ rule without the safety factors), again based on Eq. (2) and using the elastic follow up factor, is introduced in the ISDC to limit the local plastic strain to the true strain at rupture after correction for triaxiality of the stress field.

$$
S_{d}=S_{t r}+\frac{E}{r_{2}} \frac{\varepsilon_{t r}}{T F}
$$

where $S_{t r}$ is the true stress at rupture and

in a zone of stress concentration $\left(\overline{\mathrm{P}_{\mathrm{L}}+\mathrm{P}_{\mathrm{b}}+\mathrm{Q}+\mathrm{F}}\right)$

$\mathrm{r}_{2}=\mathrm{K}_{\mathrm{T}}$,

and away from zones of stress concentrations or excluding peak stresses $\left(\overline{\mathrm{P}_{\mathrm{L}}+\mathrm{P}_{\mathrm{b}}+\mathrm{Q}}\right.$;

$$
r_{2}=\left\{\begin{array}{l}
4 \text { if } \varepsilon_{\mathrm{u}} \geq 2 \% \\
\infty \text { if } \varepsilon_{\mathrm{u}}<2 \%
\end{array}\right.
$$

This damage is not of concern for type $316 \mathrm{LN}$-IG stainless steel whose ductility as measured by per cent reduction in area is not appreciably reduced by irradiation [3]. 


\section{Conclusions}

Simple rules to account for the loss of uniform elongation (strain hardening) and true strain at rupture due to irradiation have been included in the ISDC. First, the bending shape factor for primary bending stress has been redefined to account for possible loss of

ductility. Second, new elastic-analysis rules for combined primary and secondary stresses have been included using the concept of elastic follow up factor (r-factor) which can be used to estimate the actual stress and plastic strain in a structure conservatively.

Available three-point bend and notched tensile test data on irradiated type 304 stainless steel have been compared with analytical model predictions to validate the $r$-factor methodology for these tests. Based on these tests and analytical predictions, the value of the r-factor has been set equal to infinity when the uniform elongation of the material drops below $2 \%$. For higher values of uniform elongation, the value of $r$ has been set equal to the greater of 4 and the stress concentration factor $\mathrm{K}_{\mathrm{T}}$.

\section{References}

1. ASME Boiler and Pressure Vessel Code, Section III, Division 1, Subsection NB. Edition July 1995.

2. RCC-MR. Design and Construction Rules for Mechanical Components of FBR Nuclear Islands. Section I, Subsection B: Class 1 components. edition 1985

3. A. A. Tavassoli, Assessment of Austenitic Stainless Steels, ITER Task BL-URD3 Report F. A. 3591-ITER, June 1994.

4. F.M. Haggag, W.L. Server, W.G. Reuter, and J. M. Beeston, Effects of irradiation fluence and creep on fracture toughness of type 347/348 stainless steel, in: Effects of radiation on materials, Vol. 2, ed. Garner/Perrin (ASTM STP 870, 1985), pp. 548562.

5. M.I. de Vries and D.J. Michel, Fatigue crack growth in neutron-irradiated type 304 and type 316 stainless steels, in: Effects of radiation on materials, Vol. 2, ed. Garner/Perrin (ASTM STP 870, 1985), pp. 803-819. 
6. R. L. Roche, Simplified elastic-plastic fatigue analysis using an elastic follow-up method, in: Fatigue and fracture, ASME-PVP 103, pp. 95-99, Chicago, 1986

7 K. Iida, Y. Asada, K. Ikavayashi, and T. Nagata, Simplified analysis and design for elevated temperature component of MANJU, in: Nuclear Eng. and Design, Vol. 98, pp. 314-317, 1987.

8 K. Takakura, U. Masahiro, M. Ichimiya, H. Hirayama, T. Ueno, H. Wada, H. Ozaki, and T. Ohsaki, Development of elevated temperature structural design guide for Japanese demonstration breeder reactor, Nucl. Eng. and Design, Vol. 155, pp. 559-570, 1995.

9 H. D. Garkisch, R. L. Fish, and D. R. Haglund, Irradiated EBR-II Duct Crushing Test and Analysis, WARD-D-0164, January, 1977.

10 R. L. Fish, Notch Effect on the Tensile Properties of Fast-reactor Irradiated Type 304 Stainless Steel, Nucl. Tech., Vol. 31, October, 1976. 


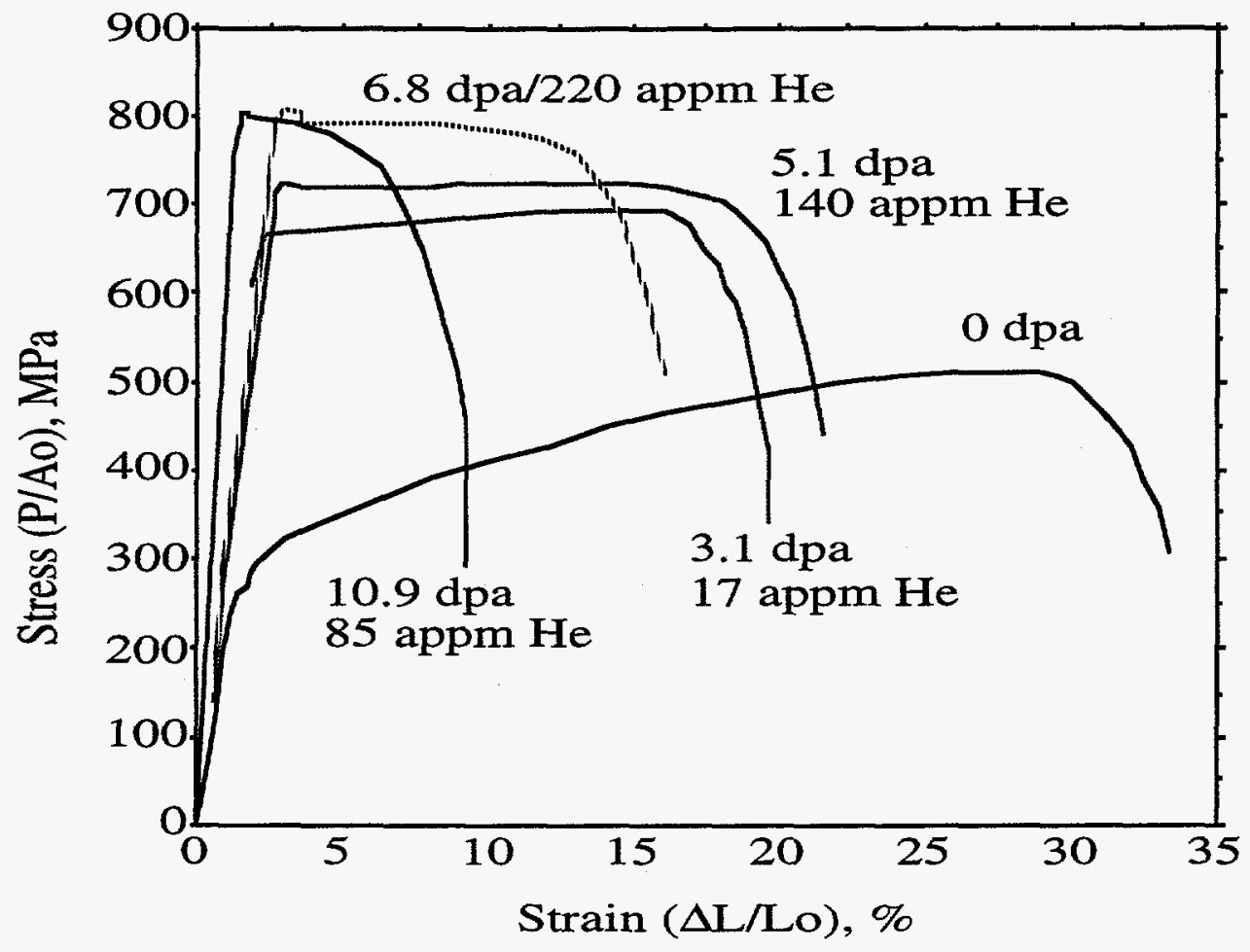

Figure 1 Typical variation of the uniaxial stress-strain curve of Type 316 LN-IG stainless steel with fluence 


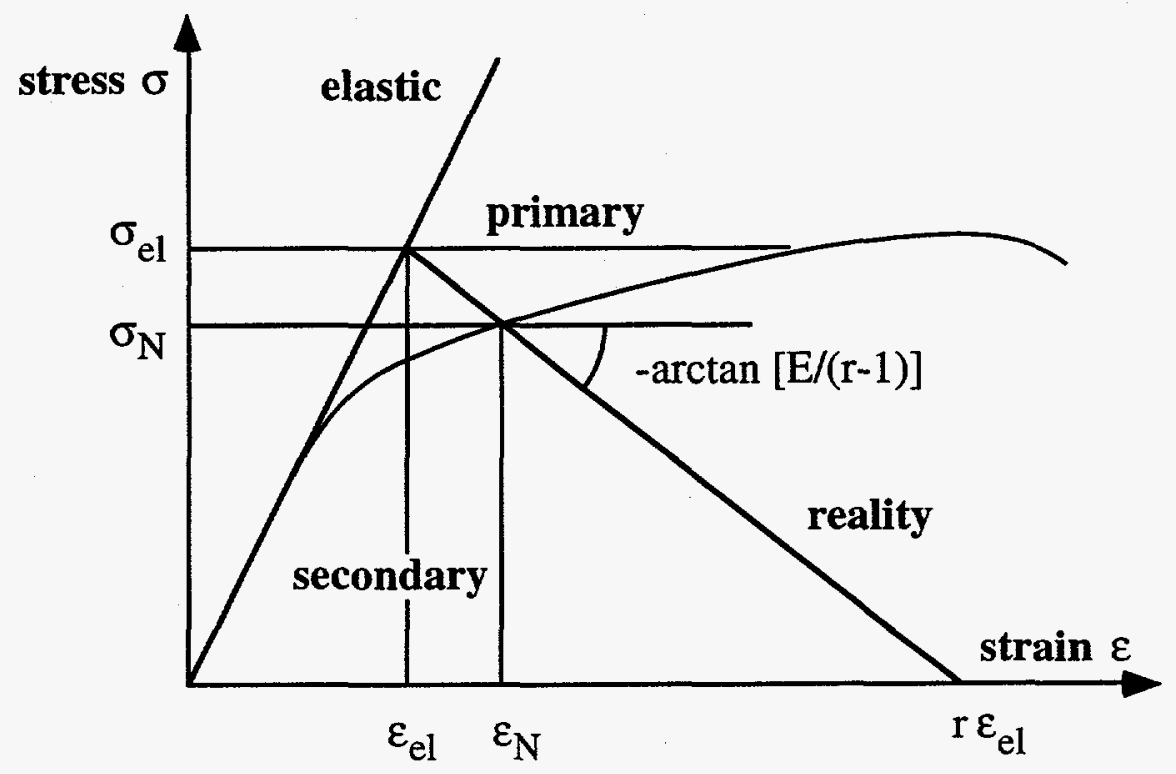

Figure 2

Definition of elastic follow up factor, $r$ 


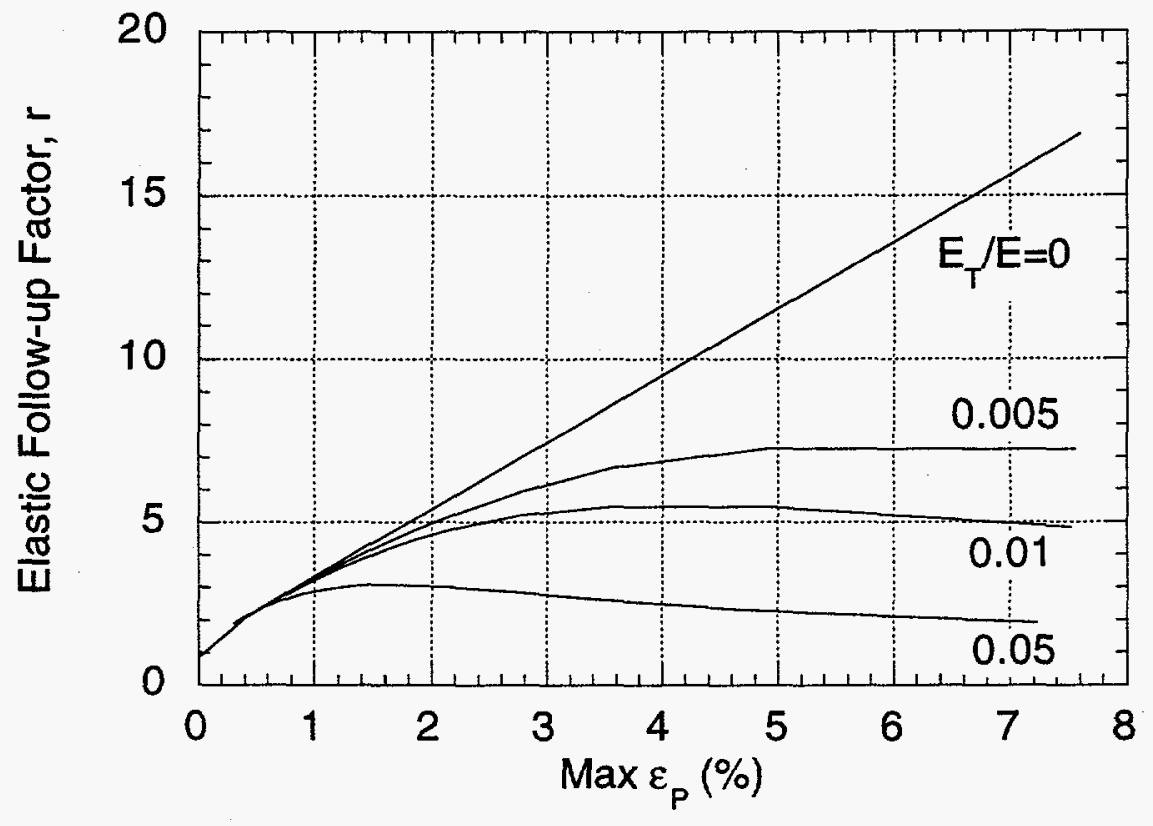

Figure 3

Effect of strain hardening (tangent modulus $\mathrm{E}_{\mathrm{T}}$ ) on the $r$-factor variation with maximum plastic strain for 3-point bend tests 


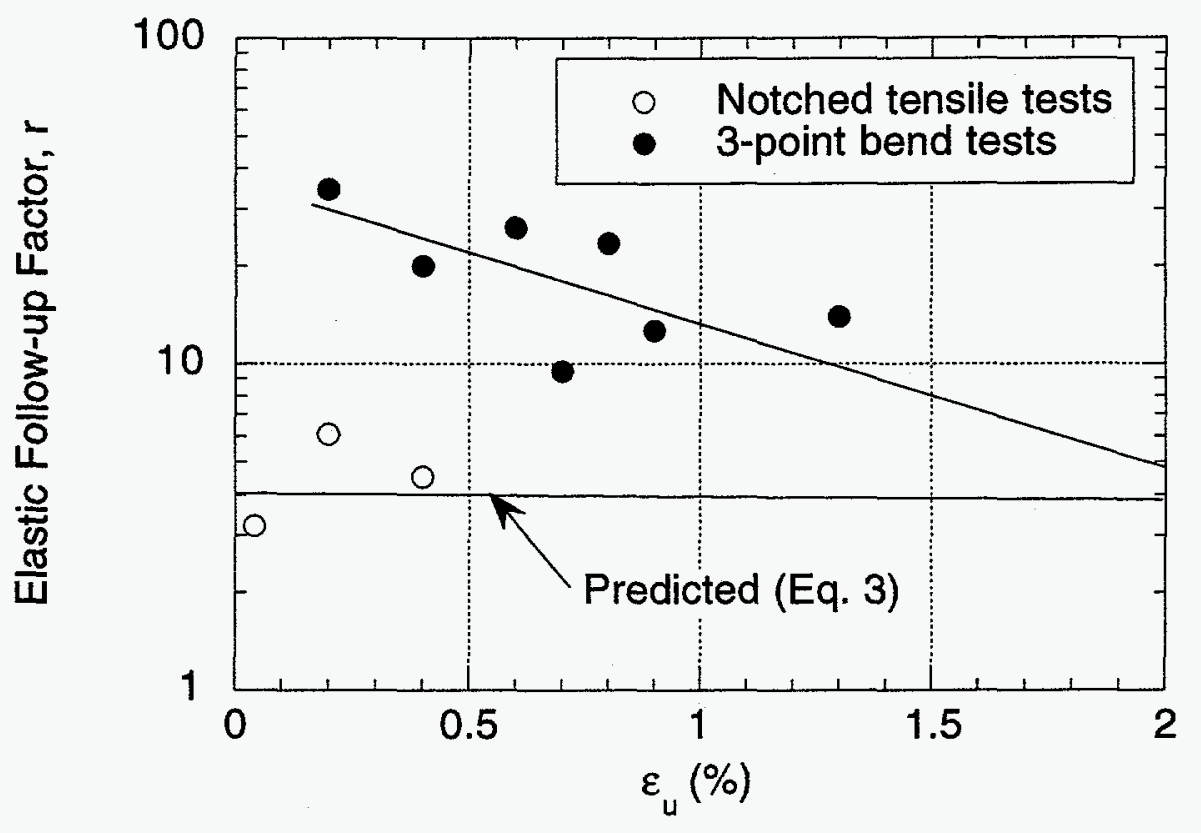

Figure 4

Calculated r-factors from 3-point bend tests and notched tensile tests on irradiated type 304 stainless steel 


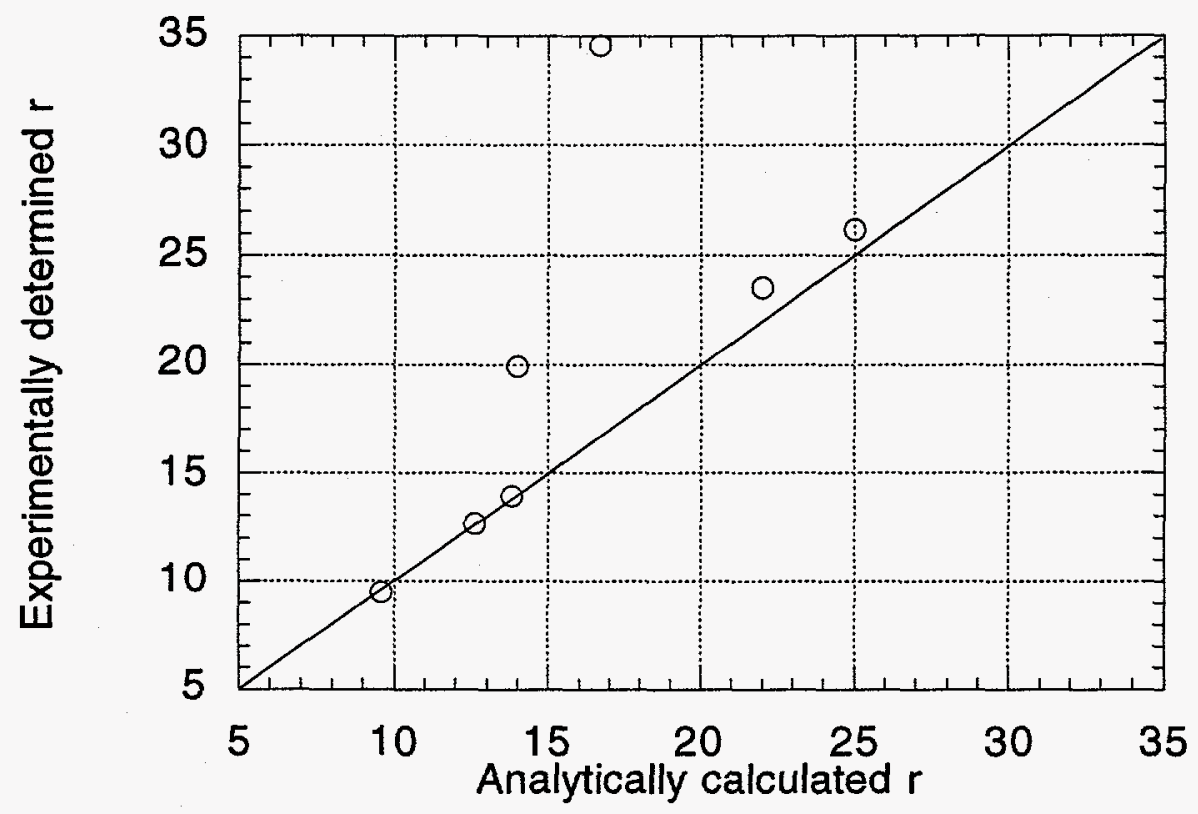

Fig. 5

Comparison of r-factors calculated from test data with those calculated analytically for three-point bend tests on irradiated type $\mathbf{3 0 4}$ austenitic stainless steel. 


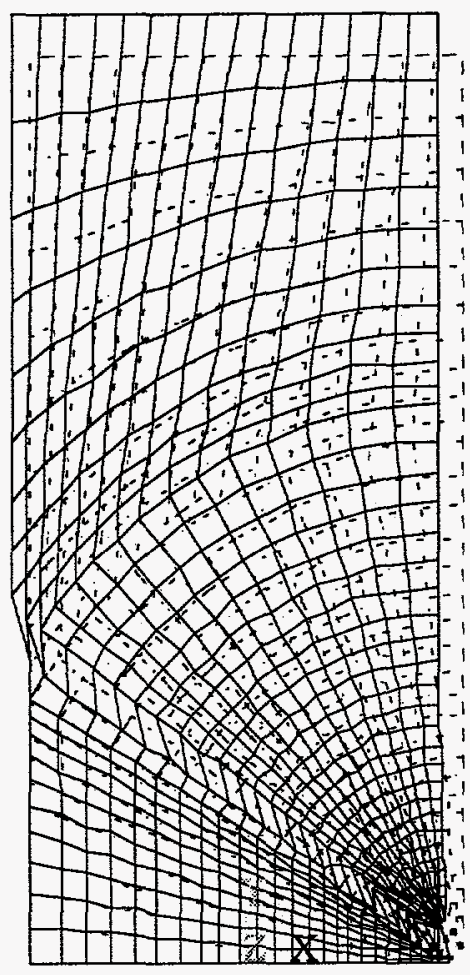

Figure 6

Displaced shape indicating flow localization phenomenon for the case of plane stress. 


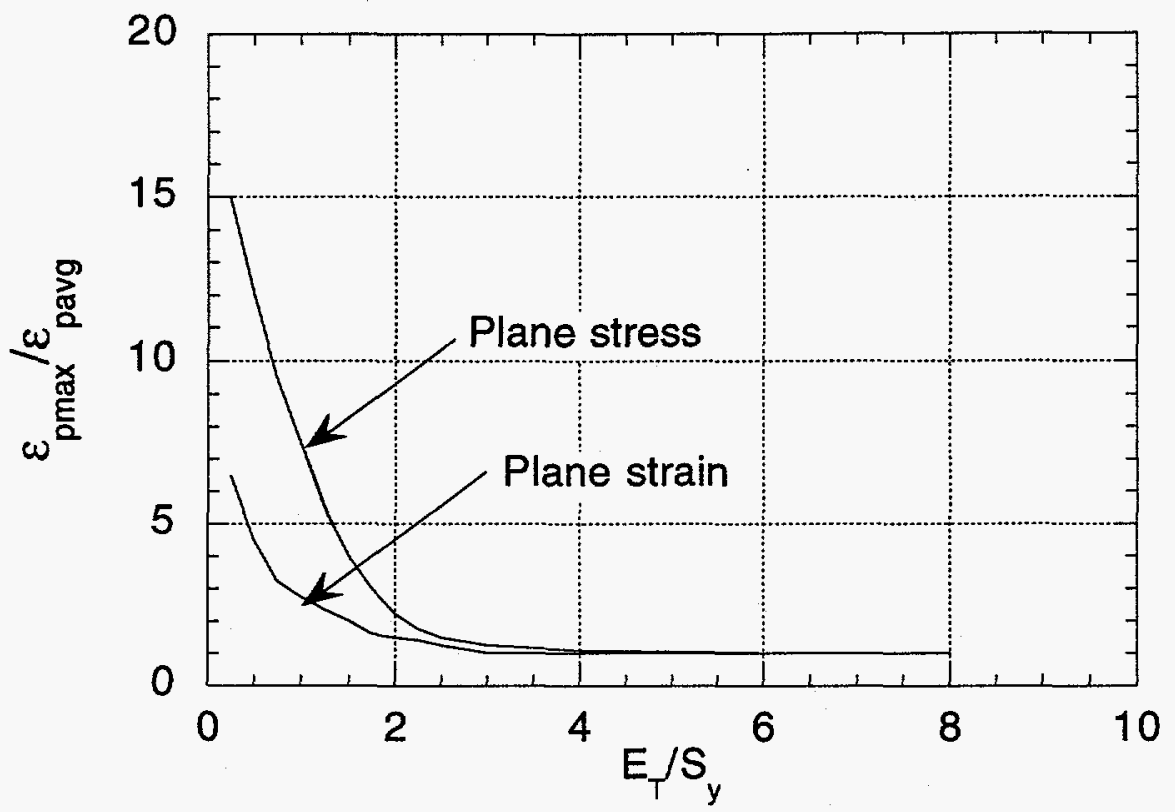

Figure 7

Variation of calculated peak plastic strain (normalized by the average plastic strain) in the opposite surface from the one containing the notch with tangent modulus (normalized by the yield stress) for the notched tensile test. 